\title{
Extraction of Antioxidant Total Phenol from Lees of Xiaoqu Spirits
}

\author{
Xinzhi Cao*, Fang Liu, Jia Liu, Xiao Tan, Linsheng Ren \\ Applied Institute of Food and Biotechnology, Sichuan Science and Technology College, Zigong, China \\ Email: ${ }^{*}$ caoxinzhi@163.com
}

Received 14 March 2015; accepted 21 August 2015; published 26 August 2015

Copyright (C) 2015 by authors and Scientific Research Publishing Inc.

This work is licensed under the Creative Commons Attribution International License (CC BY). http://creativecommons.org/licenses/by/4.0/

(c) () O) Open Access

\section{Abstract}

By the Soxhlet extraction, ethanol is used as extraction solvent of lees to determinate the total phenol content of Xiaoqu spirits lees. Folin-phenol method is handled to extract and to determine the reducing ability of extraction. The total phenolic content in the most suitable condition is determinated by the Folin-phenol method and the optimum extraction technological condition of total phenol is determinated by the experiment. The experimental results show that the optimization conditions of the determination methods of total phenolic content are determined by $3.5 \mathrm{~mL}$ for the Folin phenol reagent, $1: 1$ for the $10 \% \mathrm{Na}_{2} \mathrm{CO}_{3}$ ratio and $30 \mathrm{~min}$ for the chromogenic reaction at room temperature. The optimum extraction technological condition of total phenol from lees is as following: solid-liquid ratio $1: 12$, ethanol concentration $100 \%$, extraction temperature $80^{\circ} \mathrm{C}$, extraction time $10 \mathrm{~h}$.

\section{Keywords}

Xiaoqu Spirits, Lees, Extraction, Total Phenols

\section{Introduction}

Antioxidants are a material that can delay or prevent the oxidation of the substrate at low concentrations and are widely used in food, medicine, cosmetics and other fields [1] [2]. For a long time, people have used the synthetic antioxidants in order to preserve and prevent oxidation. In recent years, research about seeking natural antioxidants from nature has attracted scientists' attention from various countries, the natural antioxidants that have been developed or are studying mainly include spice extracts, polyphenols, natural flavonoids, vitamins, proteins and enzymes, phytic acid, herbal extracts, etc. [3]-[5]. The small liquor distiller's grains were used as raw material in this experiment to extract the natural antioxidants total phenolic, and measure its reducing ability. This

${ }^{*}$ Corresponding author. 
topic provides a theoretical basis for the development and application of natural antioxidants, and plays an active role in the utilization of wine lees byproduct and environmental protection.

\subsection{Materials and Methods}

\subsubsection{Experimental Materials}

Ditty lees were provided by Tanks Wine Co. in Sichuan.

\subsubsection{Laboratory Equipment and Instruments}

HH-S temperature water bath, Jiangsu Province is based Instrument Co., Ltd. Jintan; DHG-9140A electric oven, Infineon Technologies Limited in Shanghai; JA5003 electronic balance, Scientific Instrument Co., Ltd. Shanghai Heng Ping in Shanghai; DK-98-II type universal furnace, Instrument Co., Ltd., Tianjin; T6 New Century UV-V spectrophotometer, Beijing Purkinje General Instrument Co., Ltd.; LG10-2.4A high-speed centrifuge, Beijing Medical Centrifuge Plant. Soxhlet extraction tube, condenser, flat-bottomed flasks, beakers, flasks, test tubes, pipettes, etc., are conventional biochemical laboratory instruments.

\subsubsection{Experimental Drugs}

Ethanol, sodium dihydrogen phosphate dihydrate, twelve water disodium hydrogen phosphate, potassium ferricyanide, trichloroacetic acid, ferric chloride, anhydrous sodium carbonate, gallic acid, sodium tungstate, sodium molybdate, lithium sulfate, concentrated sulfuric acid, concentrated hydrochloric acid and liquid bromine were of analytical grade, and these drugs were provided by Chengdu Kelong Chemical Reagent Factory.

\subsection{Methods}

\subsubsection{Extraction of Antioxidant Total Phenol from Lees of Xiaoqu Spirits (Soxhlet Extraction)}

Putting the lees into blast drying oven at $85^{\circ} \mathrm{C}$ for $2 \mathrm{~h}$, weighing $16 \mathrm{~g}$ dried raw material in the distillers and Soxhlet extraction tube, connecting the test device, adding $160 \mathrm{~mL}$ of ethanol to a round bottom flask of the Soxhlet extracted tube, the temperature magnetic heating stirrer was used to hear it, maintaining $80^{\circ} \mathrm{C} \sim 85^{\circ} \mathrm{C}$ and refluxing fir $8 \mathrm{~h}$, till extract was cooled to room temperature, and voluming to $250 \mathrm{~mL}$ with boiled distilled water to become the sample solution.

\subsubsection{Lowry Method for the Determination of Total Phenolic Content of Extracts [6]}

Let gallic acid concentration $(\mu \mathrm{g} / \mathrm{mL})$ as the abscissa, absorbance at $760 \mathrm{~nm}$ value as the vertical axis, then we make gallic acid standard curve. Taking $1 \mathrm{~mL}$ sample solution in $100 \mathrm{~mL}$ graduated test tube with stopper, joining Folin phenol reagent $3.5 \mathrm{~mL}$, adding $10 \% \mathrm{Na}_{2} \mathrm{CO}_{3} 3.5 \mathrm{~mL}$ after 7 to 8 minutes, after reaction at room temperature for $1 \mathrm{~h}$, voluming to $100 \mathrm{~mL}$ with distilled water, then shaking it. Distilled water is as the reference solution, by adjusting the wavelength of $760 \mathrm{~nm}$, measuring the absorbance, we could get the total phenol concentration in the solution from the standard curve of total phenolic content, resulting in total phenolic content of the sample. Isolating on standard curves corresponds to the amount of total phenols, calculating formula of the total phenolic content in the sample was as follows:

$$
\text { Total phenol } / \%=0.00375 \mathrm{G} / \mathrm{W} \times 100 \%
$$

$\mathrm{G}$ is the total amount of phenol $(\mu \mathrm{g})$ from the standard curve, $\mathrm{W}$ is the sample weight $(\mathrm{g})$.

\subsubsection{Reducing Ability Determination of Grains Extract [7] [8]}

Taking $1 \mathrm{~mL}$ extract (blank tube by adding an equal volume of $80 \%$ ethanol), adding $0.2 \mathrm{~mol} / \mathrm{L}$, pH 6.6 sodium phosphate buffer $1.0 \mathrm{~mL}$ and $1 \%$ potassium ferricyanide $1.0 \mathrm{~mL}$, rapid cooling after reaction at $50^{\circ} \mathrm{C}$ water bath for $20 \mathrm{~min}$, adding $10 \%$ trichloroacetic acid $1.0 \mathrm{~mL}$, adding distilled water to a final volume of $10 \mathrm{~mL}, 3000$ $\mathrm{r} / \mathrm{min}$ centrifugal $10 \mathrm{~min}$, supernatant $2.5 \mathrm{~mL}$, adding $0.1 \%$ ferric chloride solution $0.5 \mathrm{~mL}$, voluming to $5 \mathrm{~mL}$ with distilled water after mixing, measuring the $700 \mathrm{~nm}$ absorbance after $10 \mathrm{~min}$. Calculated formula was as follows:

$$
\text { Reducing power }=(\text { A sample }- \text { A blank }) / \text { A blank } \times 100 \%
$$




\subsubsection{The Study of Total Phenol Content Lowry Assay Conditions}

The optimum conditions of Folin phenol method that was used to measure the total phenolic content were determined through determining the reagent, reaction temperature and reaction time.

\subsubsection{The Research of Total Phenol Extraction Process Conditions from Grains}

Through single factor and orthogonal experiments, we measure alcohol concentration, extraction temperature, solid-liquid ratio and extraction time on the heat reflux extraction and determine the optimum extraction conditions of total phenols.

\section{Results and Analysis}

\subsection{The Optimum Conditions for Total Phenolic Content of Lowry Assay}

\subsubsection{Determination of the Amount of Reagent}

The steps of determination of Folin phenol reagent and $10 \% \mathrm{Na}_{2} \mathrm{CO}_{3}$ proportional is: taking $0.5 \mathrm{~mL}$ gallic acid standard solution, adding Folin phenol reagent $3.5 \mathrm{~mL}$, adding different volumes of $10 \% \mathrm{Na}_{2} \mathrm{CO}_{3}$ solution according to Table 1 after $7 \sim 8 \mathrm{~min}$, voluming to $100 \mathrm{~mL}$ and measuring absorbance values after reaction at room temperature for $1 \mathrm{~h}$, the measurement results are shown in Table 1.

Table 1 shows that when adding $10 \% \mathrm{Na}_{2} \mathrm{CO}_{3} 3.5 \mathrm{ml}$, ratio of Folin phenol reagent and $\mathrm{Na}_{2} \mathrm{CO}_{3}$ is $1: 1$, the absorbance value is the maximum, so chromogenic reaction is complete when ratio of Folin phenol reagent and $\mathrm{Na}_{2} \mathrm{CO}_{3}$ is $1: 1$.

The determination of Folin phenol reagent dosage: the amount of Folin phenol reagent are 0.5, 1.5, 1.0, 2.0, 2.5, 3.0, 3.5, $4.0 \mathrm{~mL}$, adding equal volume of $10 \% \mathrm{Na}_{2} \mathrm{CO}_{3}$ solution, other conditions and methods remain unchanged. The measurement results are shown in Table 2.

As apparent from Table 2, when the Folin phenol reagent addition is $3.5 \mathrm{~mL}$, the absorbance is the maximum.

\subsubsection{The Determination of the Reaction Temperature}

$3.5 \mathrm{~mL}$ Folin phenol reagent, $3.5 \mathrm{~mL} 10 \% \mathrm{Na}_{2} \mathrm{CO}_{3}$ solution, the reaction temperature are set to $5^{\circ} \mathrm{C}, 10^{\circ} \mathrm{C}, 25^{\circ} \mathrm{C}$, $35^{\circ} \mathrm{C}, 45^{\circ} \mathrm{C}$, other conditions and methods remain unchanged. The measurement results are shown in Table 3 .

As apparent from Table 3, the absorbance difference is not obvious when the temperatures are $10^{\circ} \mathrm{C}, 25^{\circ} \mathrm{C}$, $35^{\circ} \mathrm{C}$, the absorbance is the maximum value at $25^{\circ} \mathrm{C}$. Visible under normal temperature conditions, temperature has little effect on the absorbance values, illustrating that the determination of total phenolic content can be carried out at room temperature.

\subsubsection{Determination of the Reaction Time}

$3.5 \mathrm{~mL}$ Folin phenol reagent, $3.5 \mathrm{~mL} 10 \% \mathrm{Na}_{2} \mathrm{CO}_{3}$ solution, react at room temperature, other conditions and methods remain unchanged. Measuring absorbance value at a certain time interval, the measurement results are shown in Table 4.

Table 1. Effect of $10 \% \mathrm{Na}_{2} \mathrm{CO}_{3}$ quantity on extinction value.

\begin{tabular}{cccccccc}
\hline Ratio of Folin phenol reagent and $\mathrm{Na}_{2} \mathrm{CO}_{3}$ & $4: 1$ & $3: 1$ & $2: 1$ & $1: 1$ & $1: 2$ & $1: 3$ & $1: 4$ \\
\hline Absorbance & 0.126 & 0.133 & 0.138 & 0.209 & 0.205 & 0.201 & 0.192 \\
\hline
\end{tabular}

Table 2. Effect of Folin phenolic reagent quantity on extinction value.

\begin{tabular}{ccccccccccc}
\hline Folin phenol reagent/mL & 0.5 & 1.5 & 1.0 & 2.0 & 2.5 & 3.0 & 3.5 & 4.0 \\
\hline Absorbance & 0.191 & 0.211 & 0.216 & 0.221 & 0.230 & 0.240 & 0.247 & 0.215 \\
\hline
\end{tabular}

Table 3. Effect of reagent ration on extinction value.

\begin{tabular}{cccccc}
\hline Temperature $/{ }^{\circ} \mathrm{C}$ & 5 & 10 & 25 & 35 & 45 \\
\hline Absorbance & 0.156 & 0.166 & 0.168 & 0.167 \\
\hline
\end{tabular}


As apparent from Table 4, the absorbance value added to a certain value after $30 \mathrm{~min}$, and no significant effect increased with time. Therefore, the best reaction time was $30 \mathrm{~min}$.

\subsection{The Optimum Extraction Conditions of Total Phenols}

\subsubsection{Single Factor Test Results}

\section{1) The Effect of Ethanol Concentration on the Heat Reflux Extraction}

Dried distillers grains as raw material, each weighed $16 \mathrm{~g}$, solid-liquid ratio was $1: 10$, adding $40 \%, 50 \%, 65 \%$, $80 \%$, 95\% ethanol solution, heating with temperature magnetic heating stirrer, maintaining $80^{\circ} \mathrm{C} \sim 85^{\circ} \mathrm{C}$ and refluxing for $8 \mathrm{~h}$, till extract was cooled to room temperature, voluming to $250 \mathrm{~mL}$ with boiled distilled water, then determining total phenolic content and reducing power of extracts, the measurement results are shown in Figure 1.

As can be seen from Figure 1, the ethanol concentration has a significant influence on the thermal reflux extraction. When the ethanol concentration is $95 \%$, the total phenolic content and reducing power of extracts are high. Therefore, we could determine that the optimal concentration of ethanol is $95 \%$.

\section{2) The Effect of Extraction Temperature on the Heat Reflux Extraction}

Ethanol concentration was $95 \%$, extraction temperatures were set to $80^{\circ} \mathrm{C}, 85^{\circ} \mathrm{C}, 90^{\circ} \mathrm{C}, 95^{\circ} \mathrm{C}, 100^{\circ} \mathrm{C}$, other conditions and methods remained unchanged. Measurement results of the total phenolic content and reducing power of the extracts are shown in Figure 2.

Figure 2 shows the total phenolic content of the extract and reducing power decreases as the temperature rises. Because of the process of the solvent extraction mass transfer, temperature affects both dissolution rate of the solute in a solvent, but also affects the speed of the outward diffusion of solute; temperature has a great influence on the extraction of heat reflux extraction. Temperature increases, mass transfer rate increases, the diffusion speed, extraction rate will accelerate, thus heating could help improve material yield of the crude extract. But too high temperature will affect the activity of the active substance, even make it completely inactivated. Phenols are more sensitive to heat, it will accelerate the oxidation or decomposition when exposed to heat, so total phenolic content of the crude extract will vary with the temperature decrease. But warming also could improve the solubility and diffusion coefficient of phenolic compounds overall, therefore, decline in total phenolic content is relatively flat. Considering that, the optimum extraction temperature is determined to $80^{\circ} \mathrm{C}$.

\section{Table 4. Result of stability test.}

\begin{tabular}{cccccccccccccccc}
\hline Time/min & 5 & 10 & 15 & 20 & 25 & 30 & 35 & 40 & 45 & 50 & 55 & 60 \\
\hline Absorbance & 0.132 & 0.164 & 0.175 & 0.203 & 0.219 & 0.246 & 0.246 & 0.247 & 0.248 & 0.248 & 0.249 & 0.249 \\
\hline
\end{tabular}

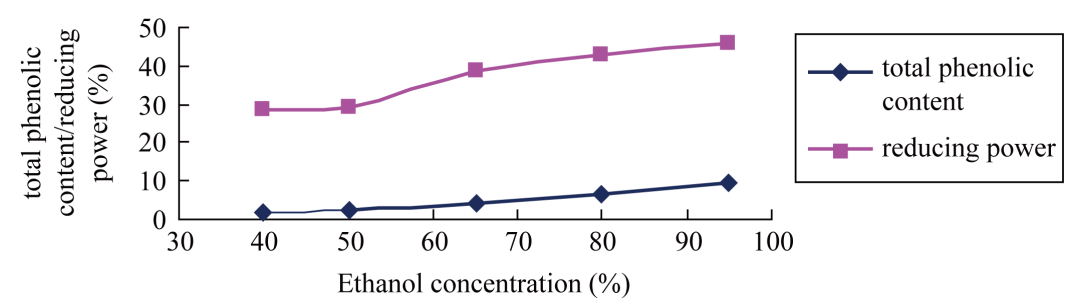

Figure 1. Effect of ethanol concentration on extraction rate.

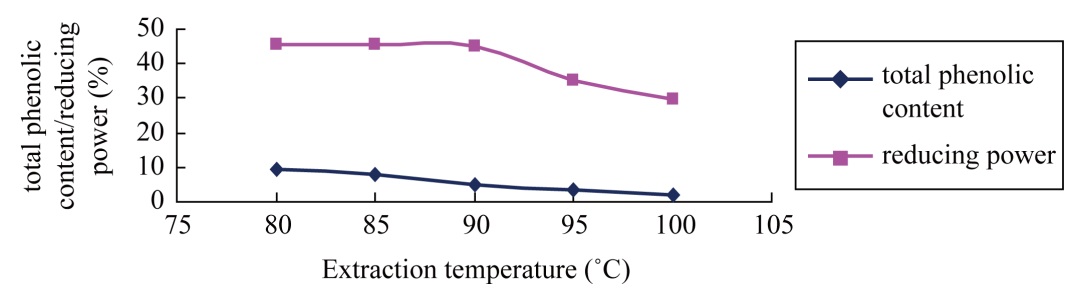

Figure 2. Effect of temperature on extraction rate. 


\section{3) The Effect of Liquid Ratio on the Heat Reflux Extraction}

Ethanol concentration was $95 \%$, extraction temperature was $80^{\circ} \mathrm{C}$, solid-liquid ratio were set to $1: 6,1: 8,1: 10$, 1:12, 1:15, other conditions and methods remain unchanged. Measurement results of the total phenolic content and reducing power of the extracts shown in Figure 3.

Figure 3 shows, the increasing of solid-liquid ratio has an impact on both total phenolic content and reducing power in crude extracts, increasing of the solid-liquid ratio can improve the rate of diffusion and shorten the time of equilibrium concentration, improve the extraction yield, however, a large amount of solvent can affect the processing (such as distillation) burden, will also greatly increase the cost. Considering that the best solidliquid ratio was determined to 1:12.

\section{4) The Effect of Extraction Time on the Heat Reflux Extraction}

Solid-liquid ratio was $1: 12$, the ethanol concentration was $95 \%$, extraction temperature was $80^{\circ} \mathrm{C}$, extraction time were set to 4 h, 6 h, 8 h, 10 h, 12 h, other conditions and methods remain unchanged. Measurement results of the total phenolic content and reducing power of the extracts shown in Figure 4.

Figure 4 shows, the total phenolic content and reducing power of extract increased with time, but only showed a significant increase state within the first 8 h, $8 \sim 10$ h relatively gentle rise, decreased significantly after $10 \mathrm{~h}$. The solvent extraction process will take some time, refluxed for longer, the raw materials and extraction have more adequate contact, the active ingredient can be better dissolution. But reflux for too long, resulting in material heating time is long, Phenols easily oxidized at high temperatures, the polymerization, degradation and loss, so the total phenolic content will appear after the first rise in decline. Considering that the optimum extraction time is determined to $8 \mathrm{~h}$.

\subsubsection{Orthogonal Test Results}

Ethanol concentration, solid-liquid ratio, extraction time, extraction temperature was four factors, set 3 levels and L9 (34) orthogonal experiment [9], in order to determine the optimum extraction conditions of total phenols. L9 (34) factor levels are shown in Table 5, the test results shown in Table 6.

Analysis of table poor R 6, affecting the factors of the extraction rate of total phenols in descending order as follows: extraction temperature $>$ ethanol concentration $>$ extraction time $>$ solid-liquid ratio. Optimum extraction conditions of the total phenols can be derived from $\mathrm{K}$ value was A3B2C3D1, ethanol concentration was $100 \%$, solid-liquid ratio was 1:12, extraction time was $10 \mathrm{~h}$, extraction temperature was $80^{\circ} \mathrm{C}$.

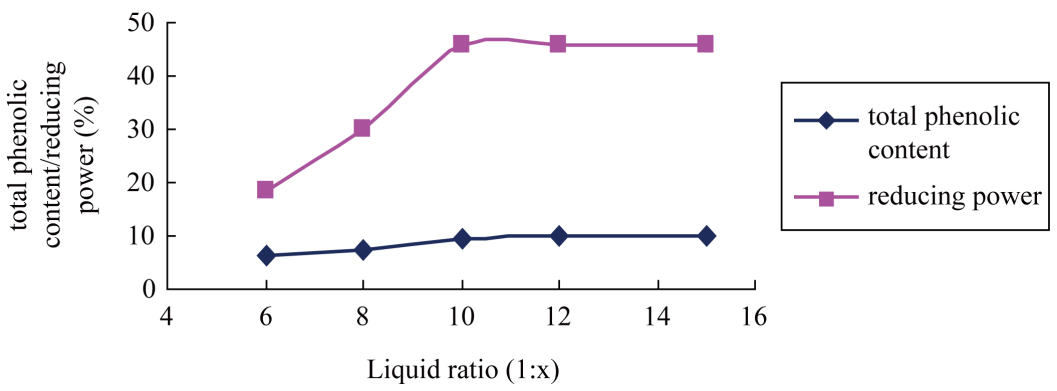

Figure 3. Effect of solid-liquid ratio on extraction rate.

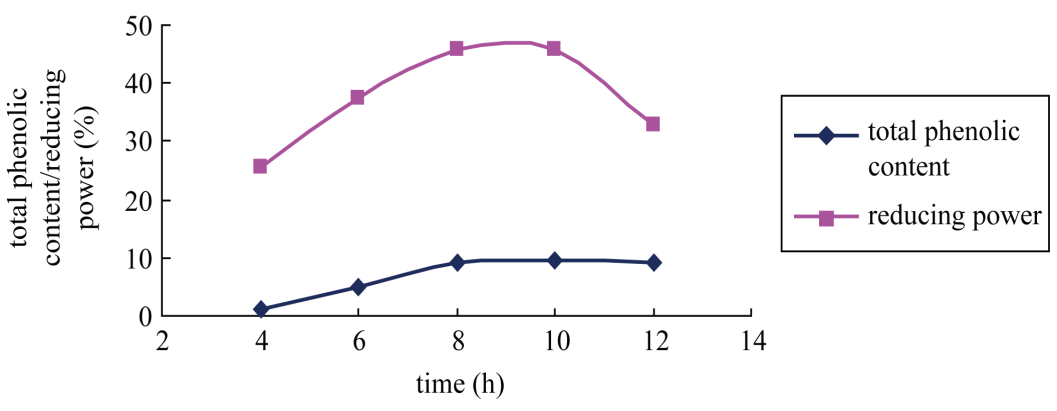

Figure 4. Effect of time on extraction rate. 
Table 5. The factor and level of orthogonal tests.

\begin{tabular}{ccccc}
\hline & & \multicolumn{3}{c}{ Factor } \\
& A-ethanol concentration/\% & B-liquid ratio & C-extraction time & D-extraction temperature \\
\cline { 2 - 5 } & 90 & $1: 10$ & 6 & 80 \\
2 & 95 & $1: 12$ & 8 & 85 \\
3 & 100 & $1: 14$ & 10 & 90 \\
\hline
\end{tabular}

Table 6. The result and analysis of orthogonal tests.

\begin{tabular}{|c|c|c|c|c|c|}
\hline \multirow{2}{*}{ Test No } & \multicolumn{4}{|c|}{ Factor } & \multirow{2}{*}{$\begin{array}{l}\text { Total pheno } \\
\text { content/\% }\end{array}$} \\
\hline & A & B & C & D & \\
\hline 1 & 1 & 1 & 1 & 1 & 8.57 \\
\hline 2 & 1 & 2 & 2 & 2 & 8.10 \\
\hline 3 & 1 & 3 & 3 & 3 & 7.45 \\
\hline 4 & 2 & 1 & 2 & 3 & 6.55 \\
\hline 5 & 2 & 2 & 3 & 1 & 9.47 \\
\hline 6 & 2 & 3 & 1 & 2 & 9.01 \\
\hline 7 & 3 & 1 & 3 & 2 & 9.23 \\
\hline 8 & 3 & 2 & 1 & 3 & 9.11 \\
\hline 9 & 3 & 3 & 2 & 1 & 9.72 \\
\hline $\mathrm{k}_{1}$ & 8.04 & 8.12 & 7.68 & 9.25 & \\
\hline $\mathrm{k}_{2}$ & 8.34 & 9.23 & 8.12 & 8.78 & \\
\hline $\mathrm{k}_{3}$ & 9.35 & 8.73 & 8.90 & 7.70 & \\
\hline $\mathrm{R}$ & 1.31 & 1.11 & 1.22 & 1.55 & \\
\hline
\end{tabular}

\section{Conclusions}

In this study, ethanol was used as the solvent in Soxhlet extraction to extract natural antioxidants total phenols from the small liquor grains, and determine its total phenolic content and the reducing ability. The conclusions were as follows:

1) Optimum conditions of Folin phenol method determines total phenolic content: Folin phenol reagent is 3.5 $\mathrm{mL}$, with $10 \% \mathrm{Na}_{2} \mathrm{CO}_{3}$ ratio of $1: 1$, and the color reaction is $30 \mathrm{~min}$ at room temperature.

2) Factors of affecting the extraction rate of total phenols in descending order are as follows: Extraction temperature $>$ ethanol concentration $>$ extraction time $>$ solid-liquid ratio. Optimum extraction conditions of Lees total phenols were as follows: Liquid ratio $1: 12,100 \%$ ethanol concentration, extraction temperature $80^{\circ} \mathrm{C}$, extraction time $10 \mathrm{~h}$.

3) In this study, providing a theoretical basis for the development and application of natural antioxidants and wine by-product, which plays an active role in environmental protection.

\section{Acknowledgements}

The authors thank the Sichuan University of Science \& Engineering for providing the basic laboratory and laboratory equipment.

\section{References}

[1] Su, W., Lu, Z.F. and Mu, Y.C. (2008) New Breakthroughs of Sauce White Wine Lees Utilization. Wine Science and Technology, 6, 101-105. 
[2] Wang, Z.Y. and Xiao, M. (2004) Comprehensive Utilization and Its Development Prospects of Wine Lees. Wine Science and Technology, 1, 65-67.

[3] Li, S.X., Cao, X.Z., Zhong, J.B., et al. (2008) Reducing Capacity and Total Phenol Content Comparative Study of Several Herbal Antioxidant Ingredients. Anhui Agricultural Technology Studies, 36, 12755-12756.

[4] Cao, X.Z., You, J.M., Xiong, L. and Chen, Y.J. (2011) Extraction and Optimization of Detection Methods of the Total Phenols of Langjiu Lees. China Brewing, 232, 137-140.

[5] Liang, L.L. (2008) Extract and Analysis of Chinese Medicine Yuzhong Antioxidant Active Substance. Master Thesis, Jiangnan University, Wuxi, 1-22.

[6] Dugh, C.S. and Amerine, M.A. (1988) Methods for Analysis of Musts and Wines. 2nd edition, John Wiley \& Sons, New York, 203-205.

[7] Ge, L. (2005) Pomace Polyphenols Extracts and Antioxidant Research. Master's Degree Thesis, NWAFU.

[8] Wang, H. (2006) Pomace Polyphenols Extract, Isolation and Activity of Anti-Oxidation. Master's Degree Thesis, Shanxi Normal University, Xi'an.

[9] Wang, Q.D., et al. (2006) Food Experimental Design and Statistical Analysis. China Agricultural University Press, Beijing. 